\section{Digital cholangioscopy-assisted gallbladder drainage: seeing is accessing}

The single-operator cholangioscope (SOC) (SpyGlass; Boston, Scientific, Natick, Massachusetts, USA) has been available since 2005 [1], and is a useful diagnostic and therapeutic tool in the management of pancreatic and biliary diseases. The addition of digital imaging to the SOC might permit better visualization and expand the therapeutic indications [2].

A 61-year-old woman with metastatic cholangiocarcinoma presented with cholecystitis. She was not a candidate for cholecystectomy. Endoscopic retrograde cholangiopancreatography (ERCP) was performed for transcystic stent placement ( Video 1). Cholangiography showed a hilar stricture and no filling of the cystic duct on pressure injection. A digital cholangioscope (Digital Spyglass, Boston Scientific) was advanced over the wire to the hilum. Visualization showed mucosal changes consistent with malignancy. The cholangioscope was slowly pulled back down the duct until the cystic duct opening was visualized ( $\bullet$ Fig. 1 ). A wire was then advanced into the cystic duct under direct cholangioscopic visualization ( Fig.2). The wire was coiled in the cystic duct using fluoroscopy, and the cholangioscope was removed. Dilation of the cystic duct was performed using a dilating catheter. A $7 \mathrm{Fr} \times 15 \mathrm{~cm}$ doublepigtail plastic stent was then deployed, with the proximal end in the gallbladder lumen and the distal end in the duodenum. Two $8.5 \mathrm{Fr} \times 12 \mathrm{~cm}$ straight plastic stents were deployed into the intrahepatic ducts. The patient's symptoms resolved, and she was discharged home with a plan to continue chemotherapy. In conclusion, digital cholangioscopy can be instrumental in pinpointing the location of the cystic duct insertion and allowing otherwise impossible transcystic drainage.

\section{Endoscopy_UCTN_Code_TTT_1AR_2AZ}

Competing interests: Michel Kahaleh MD: has received grant support from Boston Scientific, Fujinon, EMcison, Xlumena Inc., W.L. Gore, MaunaKea, Apollo Endosurgery, Cook Endoscopy, ASPIRE Bariatrics, GI Dynamics, NinePoint Medical, Merit Medical and MI Tech. He is a consultant for Boston Scientific, Xlumena Inc., Concordia Laboratories Inc. and MaunaKea Tech.

\section{Amy Tyberg, Steven Zerbo, Michel Kahaleh, Reem Z. Sharaiha}

Division of Gastroenterology and Hepatology, Weil Cornell Medical College, Cornell University New York, New York, United States

\section{References}

1 Parsi MA. Peroral cholangioscopy in the new millennium. World J Gastroenterol 2011; 17: $1-6$

2 Sethi A, Khan AH, Shah RJ et al. ERCP with cholangiopancreatoscopy may be associated with higher rates of complications than ERCP alone: a single-center experience. Gastrointest Endosc 2011; 73: 251 -256

Bibliography

DoI http://dx.doi.org/

10.1055/s-0034-1392655

Endoscopy 2015; 47: E417

(c) Georg Thieme Verlag KG

Stuttgart · New York

ISSN 0013-726X

Corresponding author

\section{Reem Sharaiha}

Division of Gastroenterology and Hepatology

Weill Cornell Medical College

New York, NY 10021

United States

Fax: +1-646-962-0110

rzs9001@med.cornell.edu

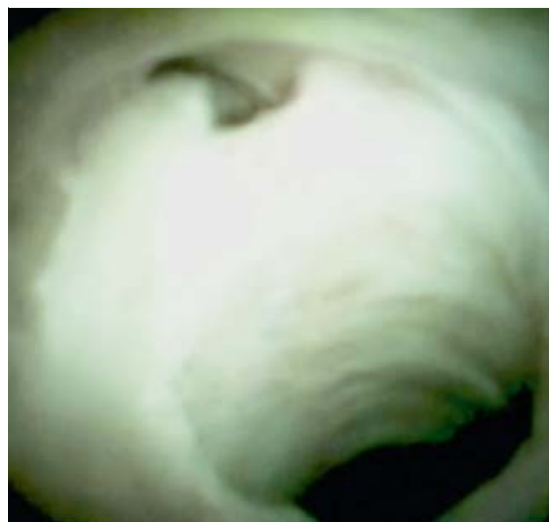

Fig. 1 Digital cholangioscopy image demonstrating cystic duct insertion, in a patient with cholecystitis and metastatic cholangiocarcinoma. This allowed gallbladder drainage in the patient, who was not a candidate for cholecystectomy.

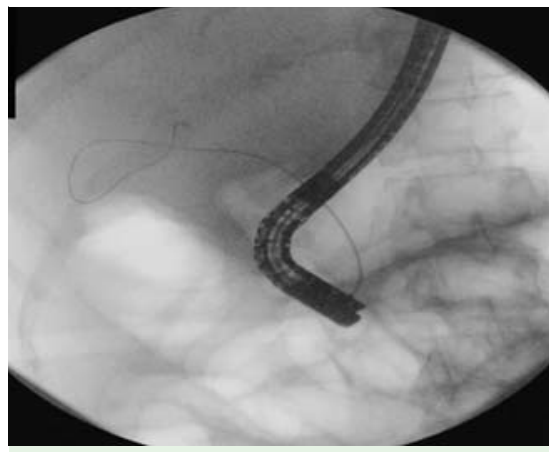

Fig. 2 Fluoroscopy image of access in the gallbladder secured with a wire.

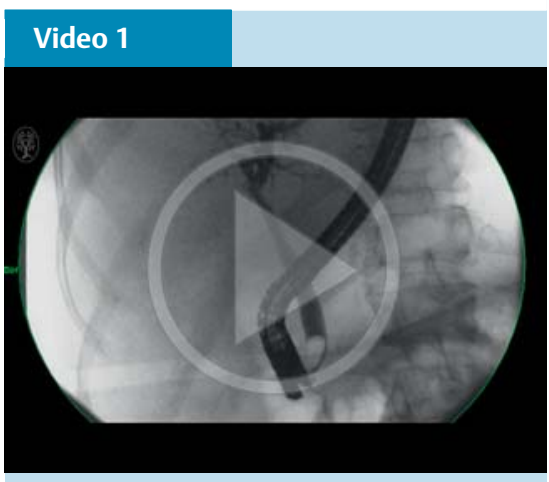

Digital cholangioscopy-assisted gallbladder drainage. 